\title{
EVoluçäo E PERSPECTIVA DA NOSSA REVISTA
}

No mês de outubro concluiu-se o mandato do grupo editorial responsável pela revista RAMB na última gestão da diretoria da AMB. Foram dois anos, oito fascículos, 194 trabalhos originais recebidos, além das novas e bemvindas seções "À beira do leito", "Panorama internacional", "Diretrizes" e "Comentário". Consolidamos a inclusão da RAMB nabiblioteca eletrônica SciELO: os artigos podem ser consultados integralmente dentro dos "sites" da AMB ou da SciELO. Os prazos de avaliação por parte dos revisores e o de publicação foram reduzidos em cerca de 40\%; hoje, o tempo médio para que um artigo aceito seja publicado é de 15 meses a partir do momento em que é recebido. As novas normas para publicação e revisão dos artigos foram instrumentos fundamentais para melhorar 0 desempenho da RAMB e aumentar o número de manuscritos submetidos à publicação. A tiragem da revista também aumentou, quadruplicando.

Apesar desses avanços que atingiram os objetivos desta gestão, a análise retrospectiva dos fascículos mostrou aspectos que merecem reflexão:

I. Mais da metade (52\%) dos artigos originais enviados são do Estado de São Paulo. Nenhum dos outros Estados brasileiros foi responsável por mais de $8 \%$ dos artigos.

2. As áreas de Clínica Médica, Cirurgia e Pediatria são responsáveis por $64 \%$ dos artigos enviados, constituindo a base científica da revista no período.
3. A taxa de aceitação dos trabalhos originais manteve-se constante, em torno de $50 \%$. Com relação às áreas, a de Clínica Médica revelou taxas de aceitação pouco maiores do que $30 \%$, sendo que outras áreas como Medicina Baseada em Evidências, Ginecologia e Obstetrícia mostraram índices de $100 \%$.

À primeira vista, parece necessário aprimorar o processo de captação de artigos científicos originais. A RAMB é uma revista indexada, classificada dentro do nível Qualis $\mathrm{Naci}$ onal A e presente nos mais importantes sistemas eletrônicos de pesquisa científica como 0 Medline eSciELO. Para a CAPES, a publicação de artigo original na RAMB é uma importante credencial na avaliação dos pesquisadores e dos cursos na pós-graduação brasileira. Então por que o recebimento de artigos ainda é menor do que o esperado?

É preciso estimular a atividade dos revisores e dos diretores regionais da AMB que são de outros Estados. A ampliação do conselho editorial pode ser útil nesta tarefa. A divulgação da RAMB também deverá ser feita junto às secretarias dos cursos de pós-graduação nas Faculdades de Medicina. Esse trabalho deverá ser acompanhado dos aumentos da tiragem e, futuramente, da periodicidade da revista, sem os quais a $A M B$ e os pesquisadores terão em mãos um instrumento pouco lido e divulgado. A tiragem da revista pode também ser ampliada por de meio exemplares eletrônicos
(CD-ROM) reduzindo assim os gastos com papel e impressão. ARAMB deverá também ser divulgada nos diversos congressos médicos do nosso País, fornecendo exemplares da revista e suas normas para publicação.

A estrutura de envio, recebimento, análise e revisão de artigos originais precisam se tornar mais ágil e responder à demanda crescente da produção científica médica brasileira. A internet deve ser o veículo preferencial neste diálogo entre o editor, o revisor e 0 autor. Maior eficiência e qualidade de revisores e editores são a garantia de divulgação de contribuições inovadoras e importantes, que sirvam de fomento para a pesquisa médica e aumentem o valor científico da RAMB, mensurável pelo índice de impacto, por exemplo.

Os trabalhos científicos brasileiros são preferencialmente enviados para revistas internacionais ou de especialidades médicas e não para a RAMB. A modificação desse comportamento só pode ser obtida com revistas de excelente qualidade, com personalidade e muito bem divulgadas. Ao escrever um artigo científico, o desejo primário e imediato do autor é ter seu trabalho visto e lido pelo maior número possível de pessoas e que este seja capaz de gerar um sem número de outras pesquisas (impacto e citações). A escolha da revista é, portanto, parte integrante do processo científico. E este $o$ horizonte que a RAMB deve buscar. 